\title{
Effects of Endogenous PPAR Agonist Nitro-Oleic Acid on Metabolic Syndrome in Obese Zucker Rats
}

\author{
Haiping Wang, ${ }^{1,2}$ Haiying Liu, ${ }^{1}$ Zhanjun Jia, ${ }^{1}$ Guangju Guan, ${ }^{2}$ and Tianxin Yang ${ }^{1}$ \\ ${ }^{1}$ Division of Nephrology and Hypertension, Department of Internal Medicine, University of Utah, 30 N 1900 E, Rm 4R312, \\ Salt Lake City, UT 84132, USA \\ ${ }^{2}$ Department of Nephrology, 2nd Affiliated Hospital, Shandong University, Jinan, China
}

Correspondence should be addressed to Tianxin Yang, tianxin.yang@hsc.utah.edu

Received 5 February 2010; Revised 29 April 2010; Accepted 8 May 2010

Academic Editor: Nanping Wang

Copyright (C) 2010 Haiping Wang et al. This is an open access article distributed under the Creative Commons Attribution License, which permits unrestricted use, distribution, and reproduction in any medium, provided the original work is properly cited.

\begin{abstract}
Nitroalkene derivatives of nitro-oleic acid $\left(\mathrm{OA}-\mathrm{NO}_{2}\right)$ are endogenous lipid products with novel signaling properties, particularly the activation of PPARs. The goal of this proposal was to examine the therapeutic potential of this $\mathrm{OA}-\mathrm{NO}_{2}$ in treatment of obesity and obesity-related conditions in obese Zucker rats. The animals were randomly divided to receive $\mathrm{OA}-\mathrm{NO}_{2}$, oleic acid $(\mathrm{OA})$, both at $7.5 \mu \mathrm{g} / \mathrm{kg} / \mathrm{d}$, or vehicle ethanol via osmotic mini-pumps for 2 weeks. Following $\mathrm{OA}-\mathrm{NO}_{2}$ treatment, food intake was decreased as early as the first day and this effect appeared to persist throughout the experimental period. At day 14, body weight gain was significantly reduced by $\mathrm{OA}-\mathrm{NO}_{2}$ treatment. This treatment significantly reduced plasma triglyceride and almost normalized plasma free fatty acid and significantly increased plasma high-density lipid (HDL). The plasma TBARS and proteinuria were paralelly decreased. In contrast, none of these parameters were affected by OA treatment. After 14 days of OA-NO hematocrit, a surrogate of fluid retention associated with PPAR $\gamma$ agonists, remained unchanged. Together, these data demonstrated that $\mathrm{OA}-\mathrm{NO}_{2}$ may offer an effective and safe therapeutic intervention for obesity and obesity-related conditions.
\end{abstract}

\section{Introduction}

The prevalence of overweight and obesity has dramatically increased during the past two decades. According to results of recent National Health and Nutrition Examination Survey (NHANES), $66.3 \%$ of adults in the United States are overweight or obese defined as a body mass index (BMI) of 25 or greater. Of these, $32.2 \%$ are obese defined as a BMI of 30 or greater [1]. The World Health Organization has estimated that worldwide, over one billion adults are overweight, with at least 300 million of them being obese [2]. Obesity is associated with a variety of chronic diseases, including endocrine disorders including metabolic syndrome, type 2 diabetes, and dislipidemia; cardiovascular disease including hypertension, congestive cardiomyopathy, stroke, and coronary heart disease; respiratory disorders including dyspnea and obstructive sleep apnea; depression, sleep disorders, musculoskeletal disorders, and gallbladder disease. Life style modification including exercise and calorie restriction remains the cornerstone of anti-obesity therapy but the long term success rate is low. In recent years, pharmacotherapy of obesity has received much attention.

Recently, nitrated free fatty acids $\left(\mathrm{NO}_{2}-\mathrm{FA}\right)$, notably nitroalkene derivatives of linoleic acid (nitrolinoleic acid, $\left.\mathrm{LNO}_{2}\right)$ and oleic acid $\left(\mathrm{OA}-\mathrm{NO}_{2}\right)$ are found to be endogenous molecules with several attractive signaling properties [3, 4]. In particular, nitroalkenes are found to be a robust endogenous ligand for peroxisome proliferator-activated receptor $\gamma(\operatorname{PPAR} \gamma)$ and they also activate $\operatorname{PPAR} \alpha$ and $\operatorname{PPAR} \delta$ at increasing concentrations [3,4]. PPARs have emerged as a novel therapeutic target for treatment of various components of metabolic syndrome. For example, synthetic PPAR $\gamma$ agonists, thiazolidinediones, have been widely used as insulin sensitizing agents for treatment of type 2 diabetes; synthetic PPAR $\alpha$ agonists such as clofibrate and fenofibrate have been used in clinics for more than 30 years as lipid lowering agents [5-8]. Unfortunately, these synthetic agents are often associated with various toxicities [7,9-11]. The goal of the present study was to examine the therapeutic potential of $\mathrm{OA}-\mathrm{NO}_{2}$ in an experimental model of obesity and metabolic syndrome. 


\section{Materials and Methods}

2.1. Animals. Four month-old male obese Zucker and lean rats were purchased from Charles River Laboratory (Wilmington, MA). All animals were housed at the University of Utah Comparative Medicine Center, maintained on a 12-hour light/dark cycle, and provided food and water ad libitum. Procedures and protocols followed guidelines set by the Laboratory Animal Care Committee at the University of Utah.

2.2. Materials. 9-Nitrooleic acid and 10-nitrooleic acid are two regioisomers of nitrooleic acid $\left(\mathrm{OA}-\mathrm{NO}_{2}\right)$. These regioisomers are formed by nitration of oleic acid in approximately equal proportions as described elsewhere [4]. The two compounds were purchased from Cayman Chemicals (Ann Arbor, MI) (9-nitrooleic acid: Cat\#10008042; 10-nitrooleic acid: Cat\#10008043) and used as a 1:1 mixture of the isomers.

2.3. Protocols for Animal Experiments. Under general anesthesia, obese Zucker rats were subcutaneously implanted with a mini-pump (DURECT Corporation, Cupertino, CA) delivering $\mathrm{OA}-\mathrm{NO}_{2}$, oleic acid (OA), both at $7.5 \mu \mathrm{g} / \mathrm{kg} / \mathrm{d}$, or vehicle ethanol for 2 weeks. Age and gender matched lean rats with vehicle treatment were used as controls. Food intake was determined periodically; body weight and collections of blood and 24-h urine samples were determined at the end of the experiments. Animals were fasted from 6:00 pm to 9:00 am before blood sampling. Blood sampling was conducted by making a small cut $(\sim 2 \mathrm{~mm})$ in the tail using razor blade. 24-hour urine was collected using metabolic cages.

2.4. Plasma Glucose and Lipids. The following determinations were analyzed by using ROCHE, Modular P in the University Hospital Chemistry Laboratory: glucose, cholesterol, triglyceride, HDL, and LDL; non-esterided fatty acids were determined by using a colorimetric method (Cat\# SFA-5, ZenBio, Research Triangle Park, NC).

2.5. Hematocrit. Hematocrit was determined as the popular ways. Briefly, 5-10 $\mu$ l of blood was collected from tail cut using a $10 \mu \mathrm{l}$ capillary glass (Idaho Technology). One side of the tube was sealed with Hemato-Seal and then centrifuged for 4 minutes in a Thermo IEC microcentrifuge machine. The total height of sample and height of the red blood cell column were measured. The hematocrit reflects the ratio between the red blood cell column and total height.

2.6. Measurement of Thiobarbituric Acid-Reactive Substances (TBARS). The measurement of TBARS was based on the formation of malondialdehyde (MDA) by using a commercially available TBARS Assay kit (Cat\#: 10009055, Cayman Chemical, Ann Arbor, MI).

2.7. Total Urine Protein. 24-h urinary protein excretion was measured by using Commassie blue.

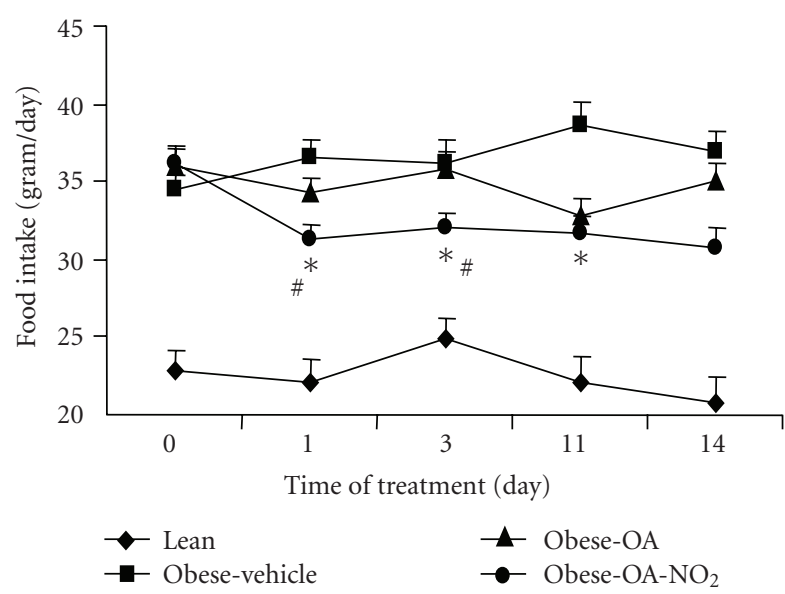

Figure 1: Food intake in male 4-mo-old obese Zucker rats (obese) over 14 days of infusion with vehicle, $\mathrm{OA}-\mathrm{NO}_{2}$, or $\mathrm{OA}$, each at $7.5 \mu \mathrm{g} / \mathrm{kg} / \mathrm{d}$ via osmotic mini-pumps. Age and gender matched lean rats with vehicle treatment were used as controls. Lean: $n=3$; Vehicle: $n=7$; OA- $\mathrm{NO}_{2}: n=5$; OA: $n=5 .{ }^{*}, P<.01$ versus Obese/Vehicle; ${ }^{*}, P<.05$ versus $\mathrm{OA}$ during the corresponding period. Data are mean \pm SE.

2.8. Statistical Analyses. All data are presented as means \pm SEM. Differences between groups were analyzed by unpaired $t$ test or 2-way ANOVA, followed by Bonferroni post hoc test using GraphPad Prism software version 3.03 (GraphPad Software, San Diego, CA). Differences within groups, before and after $\mathrm{OA}-\mathrm{NO}_{2}$ treatment, were analyzed by paired $t$ test. A probability value of $<0.05$ was considered significant.

\section{Results}

3.1. Effect of $\mathrm{OA}-\mathrm{NO}_{2}$ on Food Intake and Body Weight Gain. Starting from 4 months of age, the obese Zucker rats were chronically infused for 2 weeks with vehicle, $\mathrm{OA}-\mathrm{NO}_{2}$ or OA each at $7.5 \mu \mathrm{g} / \mathrm{kg} /$ day via an osmotic mini-pump. Untreated age-matched lean rats were used as controls. As shown in Figure 1, OA-NO $\mathrm{NO}_{2}$ treatment in obese Zucker rats reduced food intake as early as day 1 (Vehicle $36.6 \pm 1.01$ versus OA-NO $231.2 \pm 1.04 \mathrm{~g}, P<.01$ ), and this effect appeared to persist throughout the experiment except that only a trend was detected on day 14. Over the 14-day period, obese Zucker rats exhibited a significant increase in body weight as compared with lean controls (obese Zucker $48.0 \pm 4.0$ versus lean $16.7 \pm 1.2 \mathrm{~g}, P<.01)$. The body weight gain in obese Zucker rats was reduced to $34.0 \pm 1.1 \mathrm{~g}$ by $\mathrm{OA}-\mathrm{NO}_{2}$ treatment $(P<.05)$. In contrast, a 14 -day treatment with $\mathrm{OA}$ in obese Zucker rats at the same dose and same infusion rate did not affect food intake or body weight.

3.2. Effect of $\mathrm{OA}-\mathrm{NO}_{2}$ on Biochemical Parameters. At baseline, obese Zucker rats already developed significant hypertriglyceridemia as compared with lean controls (549.1 \pm 63.4 versus $78.0 \pm 11.2 \mathrm{mg} / \mathrm{dl}, P<.01)$ and the values continued to rise on day 14 . The baseline values of plasma triglyceride in the $\mathrm{OA}-\mathrm{NO}_{2}$ and $\mathrm{OA}$ groups $\left(\mathrm{OA}-\mathrm{NO}_{2}: 556.8 \pm 45.8 \mathrm{mg} / \mathrm{dl}\right.$; 


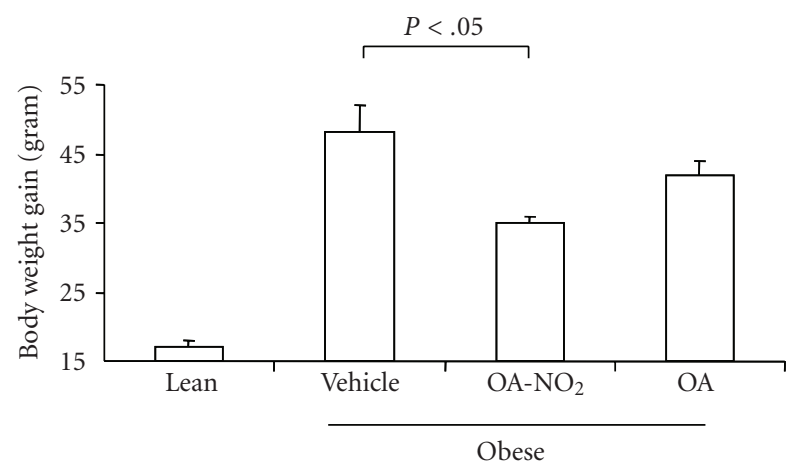

FIgURE 2: Body weight gain in obese Zucker rats before and after 14-d infusion with vehicle, $\mathrm{OA}-\mathrm{NO}_{2}$, or OA. Lean rats with vehicle treatment were used as controls. Lean: $n=3$; Vehicle: $n=7$; OA$\mathrm{NO}_{2}: n=5 ; \mathrm{OA}: n=5$. Data are mean $\pm \mathrm{SE}$.

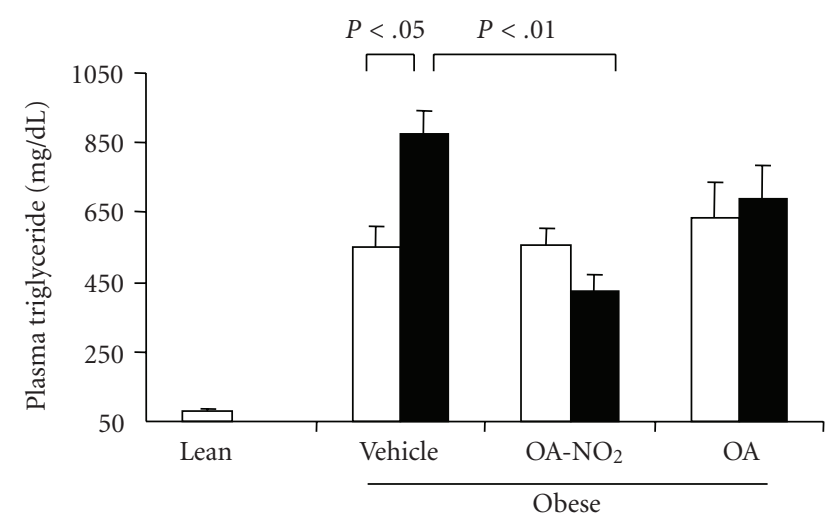

$\square$ Day 0
Day 14

FIgURE 3: Plasma triglyceride in obese Zucker rats before and after 14-d infusion with vehicle, $\mathrm{OA}-\mathrm{NO}_{2}$, or OA. Lean rats with vehicle treatment were used as controls. Lean: $n=3$; Vehicle: $n=7$; OA$\mathrm{NO}_{2}: n=5$; OA: $n=5$. Data are mean \pm SE.
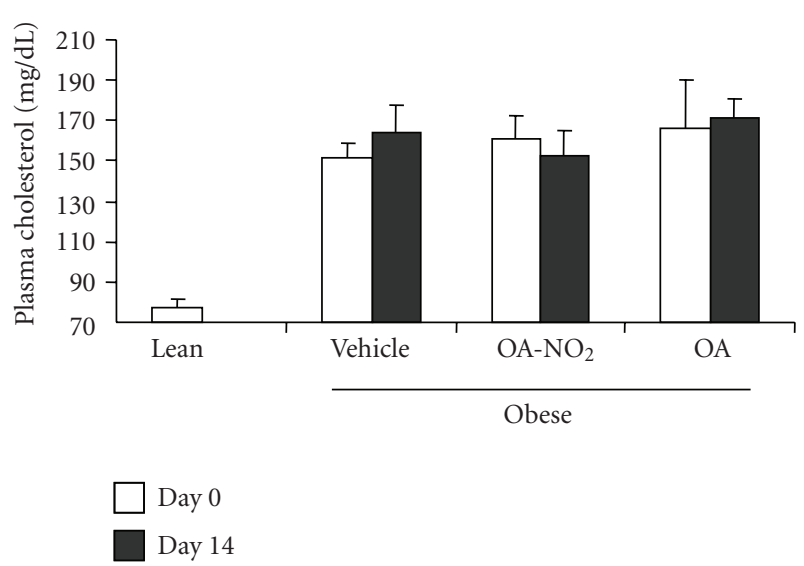

Figure 4: Plasma cholesterol in obese Zucker rats before and after 14-d infusion with vehicle, $\mathrm{OA}-\mathrm{NO}_{2}$, or OA. Lean rats with vehicle treatment were used as controls. Lean: $n=3$; Vehicle: $n=7$; OA$\mathrm{NO}_{2}: n=5$; OA: $n=5$. Data are mean \pm SE.
OA: $637.0 \pm 102.0 \mathrm{mg} / \mathrm{dl}$ ) were comparable to the vehicle group. At day 14, the values in $\mathrm{OA}-\mathrm{NO}_{2}$ group (423.0 $\pm 46.0 \mathrm{mg} / \mathrm{dl})$ but not OA group $(687.0 \pm 99.0 \mathrm{mg} / \mathrm{dl})$ was significantly lower than the vehicle control $(877.4 \pm$ $64.9 \mathrm{mg} / \mathrm{dl}$ ). Plasma non-esteried free fatty acids followed a similar pattern as plasma triglyceride. Of particular note, a 14-day treatment with $\mathrm{OA}-\mathrm{NO}_{2}$ but not $\mathrm{OA}$ decreased plasma non-esteried free fatty acid concentrations to a value almost comparable to the lean control. In contrast, plasma cholesterol was unaffected by $\mathrm{OA}-\mathrm{NO}_{2}$ or OA. Interestingly, a 14-day $\mathrm{OA}-\mathrm{NO}_{2}$ treatment elevated plasma $\mathrm{HDL}$ from 26.8 \pm 1.49 to $32.6 \pm 2.6 \mathrm{mg} / \mathrm{dl}(P<.05)$, paralleled by the increased HDL to total cholesterol ratio. In contrast, both plasma HDL and the HDL to cholesterol ratio remained unchanged after 14-day treatment with vehicle and OA. At day 14, obese Zucker rats exhibited normal glycemia $(93.7 \pm 6.9$ versus $\mathrm{mg} / \mathrm{dl})$ that was not affected by OA$\mathrm{NO}_{2}$ treatment $(85.6 \pm 5.3 \mathrm{mg} / \mathrm{dl}, P>.05)$. Plasma aspartate aminotransferase (AST)/alanine aminotransferase (ALT) and BUN were evaluated to reflect liver and kidney function, respectively; none of these parameters were affected by $\mathrm{OA}-\mathrm{NO}_{2}$ treatment (AST: $156.8 \pm 18.4$ versus $159 \pm$ $7.7 \mathrm{U} / \mathrm{L}, P>.05$; ALT: $135.0 \pm 18.9$ versus $104.5 \pm 3.9 \mathrm{U} / \mathrm{L}$, $P>.05$; BUN: $15.0 \pm 1.1$ versus $15.8 \pm 0.7 \mathrm{mg} / \mathrm{dl}, n=4-$ $5, P>.05)$. Therefore, these data do not indicate obvious hepatic or renal toxicities associated with $\mathrm{OA}-\mathrm{NO}_{2}$.

3.3. Effects of $\mathrm{OA}-\mathrm{NO}_{2}$ on Oxidative Stress, Proteinuria, and Hematocrit. Plasma TBARS was assessed as a measure of oxidative stress in obese Zucker rats. The obese rats had a marked increase in plasma TBARS as compared with lean controls $(14.83 \pm 1.47$ versus $1.97 \pm 0.63 \mu \mathrm{M}, P<.01)$. A 14-day OA- $\mathrm{NO}_{2}$ treatment decreased plasma TBARS levels to $8.26 \pm 2.31 \mu \mathrm{M}(P<.01$ versus the baseline in the same group or the vehicle group at the corresponding time period). As compared with the lean control $(12.22 \pm 0.73 \mathrm{mg} / 24$ hours), obese Zucker rats exhibited progressive proteinuria (day 0: $34.88 \pm 8.17$; day 14: $78.5 \pm 19.7 \mathrm{mg} / 24$ hours). OA treatment tended to exhibit an anti-proteuric effect but this did not reach a statistical significance.

PPAR $\gamma$ agonists are limited by significant fluid retention as reflected by body weight gain and plasma volume expansion. The drop of hematocrit has been used as a surrogate marker of plasma volume expansion since these compounds do not influence erythropoiesis. Therefore we examined hematocrit in awake animals; hematocrit remained unchanged irrespective of $\mathrm{OA}-\mathrm{NO}_{2}$ or $\mathrm{OA}$ treatment.

\section{Discussion}

linoleic acid (nitrolinoleic acid, $\mathrm{LNO}_{2}$ ) and oleic acid $\left(\mathrm{OA}-\mathrm{NO}_{2}\right)$ are two major nitroalkene derivatives formed endogenously via NO-dependent oxidative reactions [12, 13]. Studies in cell cultures have demonstrated PPAR ligand activities of these derivatives $[3,4]$. In this regard, $\mathrm{LNO}_{2}$ was initially reported to be a potent an endogenous ligand for PPAR $y$ that acts within physiological concentration ranges [3]. Subsequently, $\mathrm{OA}-\mathrm{NO}_{2}$ was shown to be a more robust 


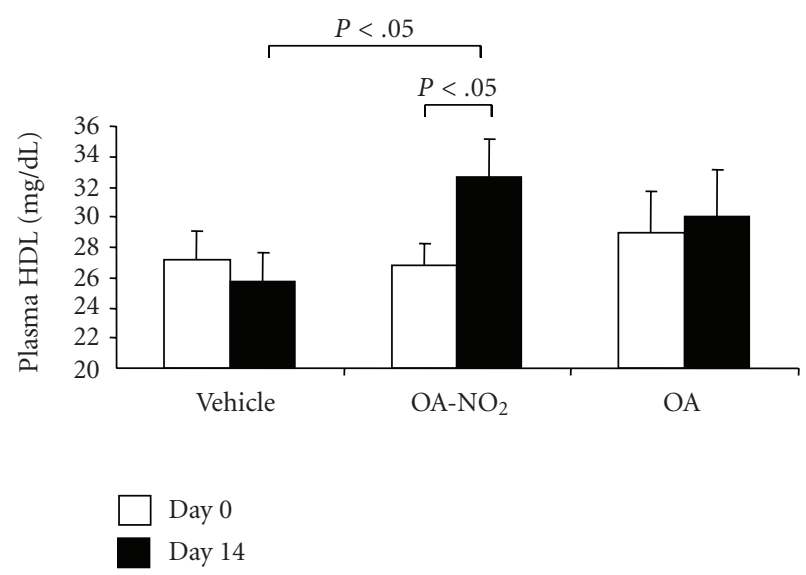

(a)

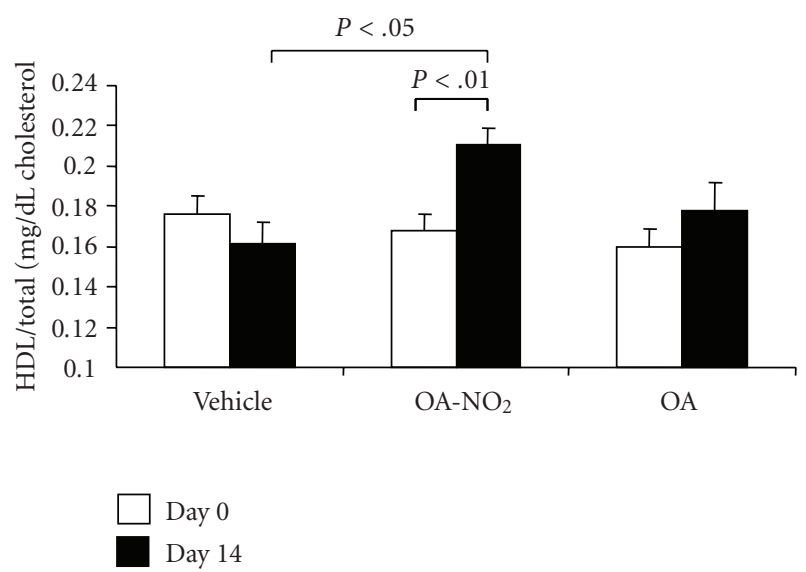

(b)

Figure 5: Plasma HDL (a) and the ratio of HDL to total cholesterol (b) before and after 14-d infusion with vehicle, $\mathrm{OA}-\mathrm{NO}_{2}$, or OA. Lean rats with vehicle treatment were used as controls. Lean: $n=3$; Vehicle: $n=7$; OA- $\mathrm{NO}_{2}: n=5$; OA: $n=5$. Data are mean \pm SE.

PPAR $\gamma$ activator as compared with $\mathrm{LNO}_{2}$ and it also activated $\operatorname{PPAR} \alpha$ and $\operatorname{PPAR} \delta$ at increasing concentrations $[3,4]$. The three subtypes of PPARs are critically important for the control of glucose homeostasis and lipid metabolism. Therefore we were prompted to evaluate the therapeutic potential of nitroalkene derivatives in an animal model of obesity and metabolic syndrome. Here we demonstrate that a 14-day osmotic delivery of a low dose $(7.5 \mu \mathrm{g} / \mathrm{kg} / \mathrm{d})$ of $\mathrm{OA}-\mathrm{NO}_{2}$ in obese Zucker rats produced beneficial effects on various components of metabolic syndrome, including obesity, hyperlipidemia, and proteinuria, accompanied by an immediate reduction of food intake.

Epidemiological studies demonstrate that ingestion of polyunsaturated fatty acids (PUFA) and monounsaturated fatty acids (MUFA) but ingestion of saturated fatty acid deteriorates insulin resistance and obesity-related diseases [14]. An issue arises as to whether the beneficial effects of $\mathrm{OA}-\mathrm{NO}_{2}$ observed in obese Zucker rats are attributable to the native OA. This possibility is not supported by a previous study showing that chronic administration of

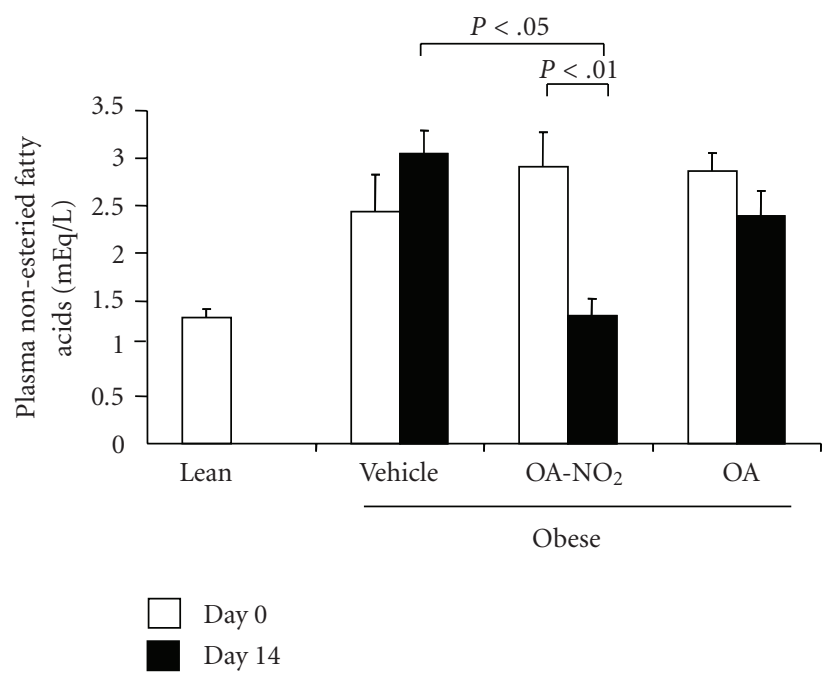

Figure 6: Plasma non-esteried fatty acids in obese Zucker rats before and after 14-d infusion with vehicle, $\mathrm{OA}-\mathrm{NO}_{2}$, or OA. Lean rats with vehicle treatment were used as controls. Lean: $n=3$; Vehicle: $n=7$; $\mathrm{OA}^{-\mathrm{NO}_{2}}: n=5$; OA: $n=5$. Data are mean \pm SE.

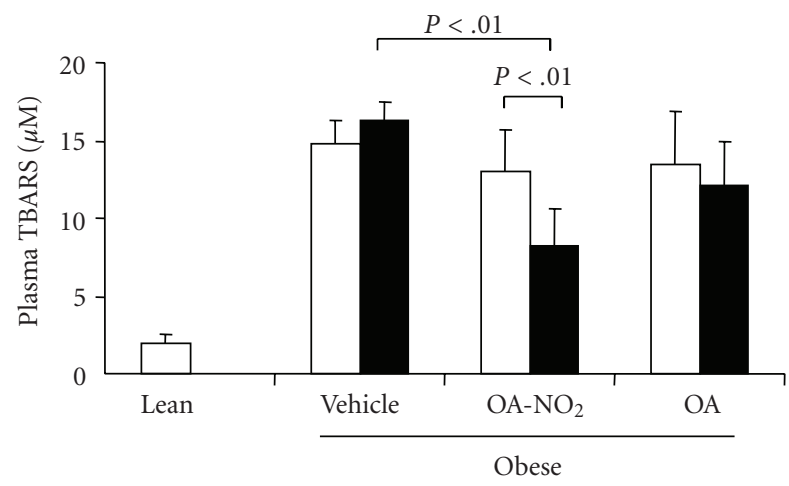

$\square$ Day 0
Day 14

Figure 7: Plasma TBARS in obese Zucker rats before and after 14$\mathrm{d}$ infusion with vehicle, $\mathrm{OA}-\mathrm{NO}_{2}$, or OA. Lean rats with vehicle treatment were used as controls. Lean: $n=3$; Vehicle: $n=7$; OA$\mathrm{NO}_{2}: n=5 ; \mathrm{OA}: n=5$. Data are mean $\pm \mathrm{SE}$.

dietary oleic acid in obese Zucker at a dose roughly 500 times higher than that in the present study fails to affect body weight, plasma glucose and lipids despite the amelioration of pancreatic islet disruption [15]. Along this line, the benefits of omega-3 polyunsaturated fatty acid (LC omega-3 PUFA) are also seen with a substantially high dose [16]. More importantly, we found that administration of $\mathrm{OA}$ at the same dose and with the same route did not produce any measurable effects on body weight or other metabolic parameters. It appears evident that the beneficial effects of $\mathrm{OA}-\mathrm{NO}_{2}$ observed in obese Zucker rats are derived from the nitration of $\mathrm{OA}$ but not the native fatty acid. 

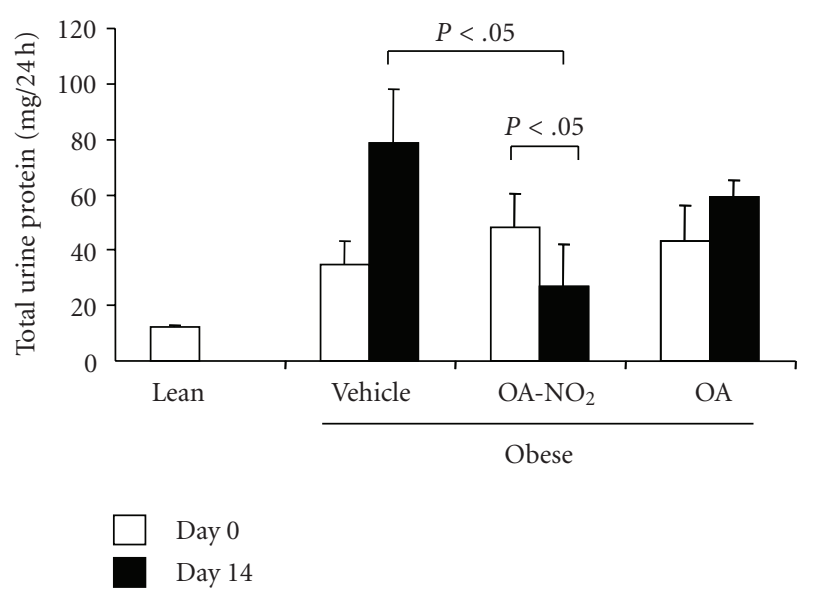

Figure 8: Proteinuria in obese Zucker rats before and after 14$\mathrm{d}$ infusion with vehicle, $\mathrm{OA}-\mathrm{NO}_{2}$, or OA. Lean rats with vehicle treatment were used as controls. Lean: $n=3$; Vehicle: $n=7$; OA$\mathrm{NO}_{2}: n=5 ; \mathrm{OA}: n=5$. Data are mean $\pm \mathrm{SE}$.
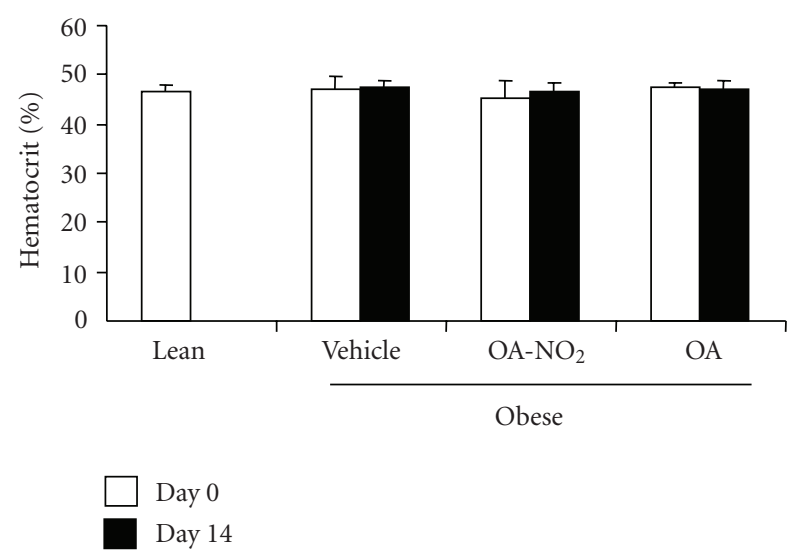

FIgure 9: Hematocrit in obese Zucker rats before and after 14$\mathrm{d}$ infusion with vehicle, $\mathrm{OA}-\mathrm{NO}_{2}$, or OA. Lean rats with vehicle treatment were used as controls. Lean: $n=3$; Vehicle: $n=7$; OA$\mathrm{NO}_{2}: n=5 ; \mathrm{OA}: n=5$. Data are mean $\pm \mathrm{SE}$.

The mechanism of action of OA- $\mathrm{NO}_{2}$ in obese Zucker rats remains elusive but the involvement of PPARs appears conceivable. PPAR $\alpha$ agonists (Wy-14643 and GW7647) and endogenous PPAR $\alpha$ agonists (oleylethanolamide;OEA) treatment induces satiety and reduces body weight gain [1720 ], an effect almost analogous to that of $\mathrm{OA}-\mathrm{NO}_{2}$ in obese Zucker rats. The rapid onset of appetite-suppressing effect (within a day) between PPAR $\alpha$ agonists and OA- $\mathrm{NO}_{2}$ is also similar. Furthermore, PPAR $\alpha$ agonists are well known to reduce plasma triglyceride and increase HDL, a profile again similar to that of OA- $\mathrm{NO}_{2}$. Together, PPAR $\alpha$ activity appears to explain most of metabolic effects of $\mathrm{OA}-\mathrm{NO}_{2}$ in obese Zucker rats. Of note, both OEA and $\mathrm{OA}-\mathrm{NO}_{2}$ are naturally occurring products derived from the same precursor, OA, and exert a similar role in regulation of satiety and body weight. It is an intriguing possibility that the two derivatives of OA converge on a common final pathway involving
PPAR $\alpha$. However, the differences may exist in regulation of their production. OEA is produced by the small intestine in response to food intake $[17,20]$ while the production of OA$\mathrm{NO}_{2}$ appears to be primarily regulated by $\mathrm{NO}$-dependent oxidative reactions which may or may not be related to feeding.

Although OA- $\mathrm{NO}_{2}$ is a robust PPAR $\gamma$ activator in an in vitro system, the involvement of PPAR $\gamma$ in $\mathrm{OA}-\mathrm{NO}_{2}$ signaling in the current experimental model might be minimal. In a sharp contrast to the appetite-suppressing and weightlowering effects of $\mathrm{OA}-\mathrm{NO}_{2}$, the synthetic PPAR $\gamma$ agonists, thiazolidinediones, cause increases in food intake $[21,22]$ and body weight and plasma volume expansion $[10,23,24]$. The lack of an effect of the PPAR $\delta / \beta$ agonist on food intake [17] also does not support involvement of $\operatorname{PPAR} \delta$ in the anorectic action of $\mathrm{OA}-\mathrm{NO}_{2}$. However, it is still possible that these two PPAR subtypes may partially contribute to some aspects of $\mathrm{OA}-\mathrm{NO}_{2}$ action, such as the lipid-lowering and proteinuria-lowering effects. Indeed, all three PPAR subtypes share common lipid-lowering properties [25-28], and PPAR $\alpha$ [29-32] and PPAR $y$ [33-36] exert similar renoprotective effects in animals or humans with diabetic nephropathy. It should be pointed out that in addition to PPARs, nitrated lipids can engage other pathways such as NO, NF-kB, and hemoxygnease-1. Whether these PPARindependent or other as yet unidentified pathways play a contributory role in mediating the metabolic actions of OA$\mathrm{NO}_{2}$ remains unclear.

Whatever the underlying mechanism, our data suggest that $\mathrm{OA}-\mathrm{NO}_{2}$ may offer therapeutic opportunities for management of obesity and obesity-related conditions. At the present, most of the anti-obesity agents target neurotransmitter receptors and are often associated with increased risk of psychiatric events. One example is rimonabant, a selective antagonist of the cannabinoid type 1 receptor, which is the most officious weight-lowering agent but causes depression and anxiety [37-39]. Because of the psychiatric side effects, the Committee for Medicinal Products for Human Use of the European Medicines Agency (EMEA) has recommended suspension of rimonabant as an antiobesity therapy [40]. $\mathrm{OA}-\mathrm{NO}_{2}$ is unique in that it is a naturally occurring product likely acting nuclear receptors, thus representing a novel class of weight-lowering agents. We demonstrated that it is not only highly effective but also well tolerated. Moreover, $\mathrm{OA}-\mathrm{NO}_{2}$ exhibited beneficial effects beyond weight loss. For example, it improved lipid profile, suppressed oxidative stress, and reduced proteinuria.

In summary, the present study describes novel therapeutic potential of OA- $\mathrm{NO}_{2}$ in a rodent model of obesity and metabolic syndrome. A low-dose treatment produces anorexia and reduces body weight gain, accompanied by improved lipid profile, and reduction of oxidative stress and proteinuria, in the absence of plasma volume expansion. These effects are derived from the nitration of OA rather than the native fatty acid. As a natural product, $\mathrm{OA}-\mathrm{NO}_{2}$ appears to be an optimal pharmacotherapy for obesity and obesity-related conditions with a superior efficacy and safety profile. 


\section{Acknowledgments}

This work was supported by Technology Commercialization Project (TCP) program from University of Utah and NIH grant DK079162. T.Y. is an Established Investigator from American Heart Association.

\section{References}

[1] C. L. Ogden, M. D. Carroll, L. R. Curtin, M. A. McDowell, C. J. Tabak, and K. M. Flegal, "Prevalence of overweight and obesity in the United States, 1999-2004," Journal of the American Medical Association, vol. 295, no. 13, pp. 1549-1555, 2006.

[2] W. H. Organization, "Obesity and overweight facts," July 2004, http://www.who.int/hpr/NPH/docs/gs_obesity.pdf.

[3] F. J. Schopfer, Y. Lin, P. R. S. Baker, et al., "Nitrolinoleic acid: an endogenous peroxisome proliferator-activated receptor $\gamma$ ligand," Proceedings of the National Academy of Sciences of the United States of America, vol. 102, no. 7, pp. 2340-2345, 2005.

[4] P. R. S. Baker, Y. Lin, F. J. Schopfer, et al., "Fatty acid transduction of nitric oxide signaling: multiple nitrated unsaturated fatty acid derivatives exist in human blood and urine and serve as endogenous peroxisome proliferator-activated receptor ligands," Journal of Biological Chemistry, vol. 280, no. 51, pp. 42464-42475, 2005.

[5] B. A. Sachs, "Appraisal of clofibrate as a hypolipidemic agent," American Heart Journal, vol. 75, no. 5, pp. 707-710, 1968.

[6] G. G. Duncan, F. A. Elliott, T. G. Duncan, and J. Schatanoff, "Some clinical potentials of chlorophenoxyisobutyrate (clofibrate) therapy (hyperlipidemia-angina pectorisblood sludging-diabetic neuropathy)," Metabolism, vol. 17, no. 5, pp. 457-473, 1968.

[7] C. Nofziger and B.L. Blazer-Yost, "PPAR $\gamma$ agonists, modulation of ion transporters, and fluid retention," Journal of the American Society of Nephrology, vol. 20, no. 12, pp. 2481-2483, 2009.

[8] W. W. Cheatham, "Peroxisome proliferator-activated receptor translational research and clinical experience," American Journal of Clinical Nutrition, vol. 91, no. 1, pp. 262S-266S, 2010.

[9] W. L. Isley, "Hepatotoxicity of thiazolidinediones," Expert Opinion on Drug Safety, vol. 2, no. 6, pp. 581-586, 2003.

[10] T. Yang, "Kidney-specific gene targeting: insight into thiazolidinedione-induced fluid retention," Nephrology, vol. 11, no. 3, pp. 201-206, 2006.

[11] J. C. Waksman, "Cardiovascular risk of rosiglitazone: another perspective," Journal of Pharmacy and Pharmacology, vol. 60, no. 12, pp. 1573-1582, 2008.

[12] P. R. S. Baker, F. J. Schopfer, S. Sweeney, and B. A. Freeman, "Red cell membrane and plasma linoleic acid nitration products: synthesis, clinical identification, and quantitation," Proceedings of the National Academy of Sciences of the United States of America, vol. 101, no. 32, pp. 11577-11582, 2004.

[13] V. Rudolph, F. J. Schopfer, N. K. H. Khoo, et al., "Nitro-fatty acid metabolome: saturation, desaturation, $\beta$-oxidation, and protein adduction," Journal of Biological Chemistry, vol. 284, no. 3, pp. 1461-1473, 2009.

[14] G. Riccardi, R. Giacco, and A. A. Rivellese, "Dietary fat, insulin sensitivity and the metabolic syndrome," Clinical Nutrition, vol. 23, no. 4, pp. 447-456, 2004.

[15] K. Sato, H. Arai, Y. Miyazawa, et al., "Palatinose and oleic acid act together to prevent pancreatic islet disruption in nondiabetic obese Zucker rats," Journal of Medical Investigation, vol. 55, no. 3-4, pp. 183-195, 2008.
[16] A. Ramel, A. Martinéz, M. Kiely, G. Morais, N. M. Bandarra, and I. Thorsdottir, "Beneficial effects of long-chain n-3 fatty acids included in an energy-restricted diet on insulin resistance in overweight and obese European young adults," Diabetologia, vol. 51, no. 7, pp. 1261-1268, 2008.

[17] J. Fu, S. Gaetani, F. Oveisi, et al., "Oleylethanolamide regulates feeding and body weight through activation of the nuclear receptor PPAR- $\alpha$," Nature, vol. 425, no. 6953, pp. 90-93, 2003.

[18] S. Terrazzino, F. Berto, M. D. Carbonare, et al., "Stearoylethanolamide exerts anorexic effects in mice via down-regulation of liver stearoyl-coenzyme A desaturase-1 mRNA expression," FASEB Journal, vol. 18, no. 13, pp. 1580-1582, 2004.

[19] G. Astarita, B. C. Rourke, J. B. Andersen, et al., "Postprandial increase of oleoylethanolamide mobilization in small intestine of the Burmese python (Python molurus)," American Journal of Physiology - Regulatory Integrative and Comparative Physiology, vol. 290, no. 5, pp. R1407-R1412, 2006.

[20] G. H. Allcock, M. Hukkanen, J. M. Polak, J. S. Pollock, and D. M. Pollock, "Increased nitric oxide synthase-3 expression in kidneys of deoxycorticosterone acetate-salt hypertensive rats," Journal of the American Society of Nephrology, vol. 10, no. 11, pp. 2283-2289, 1999.

[21] V. Emilsson, J. O'Dowd, S. Wang, et al., "The effects of rexinoids and rosiglitazone on body weight and uncoupling protein isoform expression in the Zucker fa/fa rat," Metabolism, vol. 49, no. 12, pp. 1610-1615, 2000.

[22] Q. Wang, S. Dryden, H. M. Frankish, et al., "Increased feeding in fatty Zucker rats by the thiazolidinedione BRL 49653 (rosiglitazone) and the possible involvement of leptin and hypothalamic neuropeptide Y," British Journal of Pharmacology, vol. 122, no. 7, pp. 1405-1410, 1997.

[23] W. T. Festuccia, S. Oztezcan, M. Laplante, et al., "Peroxisome proliferator-activated receptor- $\gamma$-mediated positive energy balance in the rat is associated with reduced sympathetic drive to adipose tissues and thyroid status," Endocrinology, vol. 149, no. 5, pp. 2121-2130, 2008.

[24] H. Zhang, A. Zhang, D. E. Kohan, R. D. Nelson, F. J. Gonzalez, and T. Yang, "Collecting duct-specific deletion of peroxisome proliferator-activated receptor $\gamma$ blocks thiazolidinedioneinduced fluid retention," Proceedings of the National Academy of Sciences of the United States of America, vol. 102, no. 26, pp. 9406-9411, 2005.

[25] P. de Lange, A. Lombardi, E. Silvestri, F. Goglia, A. Lanni, and M. Moreno, "Peroxisome proliferator-activated receptor delta: a conserved director of lipid homeostasis through regulation of the oxidative capacity of muscle," PPAR Research, vol. 2008, Article ID 172676, 7 pages, 2008.

[26] I. P. Torra, G. Chinetti, C. Duval, J.-C. Fruchart, and B. Staels, "Peroxisome proliferator-activated receptors: from transcriptional control to clinical practice," Current Opinion in Lipidology, vol. 12, no. 3, pp. 245-254, 2001.

[27] G. D. Barish, V. A. Narkar, and R. M. Evans, "PPAR $\delta$ : a dagger in the heart of the metabolic syndrome," Journal of Clinical Investigation, vol. 116, no. 3, pp. 590-597, 2006.

[28] G. D. Barish, "Peroxisome proliferator-activated receptors and liver X receptors in atherosclerosis and immunity," Journal of Nutrition, vol. 136, no. 3, pp. 690-694, 2006.

[29] L. F. Fried, T. J. Orchard, and B. L. Kasiske, "Effect of lipid reduction on the progression of renal disease: a meta-analysis," Kidney International, vol. 59, no. 1, pp. 260-269, 2001.

[30] X. Ruan, F. Zheng, and Y. Guan, "PPARs and the kidney in metabolic syndrome," American Journal of Physiology, vol. 294, no. 5, pp. F1032-F1047, 2008. 
[31] H. Kim, M. Haluzik, Z. Asghar, et al., "Peroxisome proliferator-activated receptor- $\alpha$ agonist treatment in a transgenic model of type 2 diabetes reverses the lipotoxic state and improves glucose homeostasis," Diabetes, vol. 52, no. 7, pp. 1770-1778, 2003.

[32] Y. M. Smolders, A. E. Van Eeden, C. D. A. Stehouwer, R. N. M. Weijers, E. H. Slaats, and J. Silberbusch, "Can reduction in hypertriglyceridaemia slow progression of microalbuminuria in patients with non-insulin-dependent diabetes mellitus?" European Journal of Clinical Investigation, vol. 27, no. 12, pp. 997-1002, 1997.

[33] P. Iglesias and J. J. Diéz, "Peroxisome proliferator-activated receptor gamma agonists in renal disease," European Journal of Endocrinology, vol. 154, no. 5, pp. 613-621, 2006.

[34] P. A. Sarafidis and G. L. Bakris, "Protection of the kidney by thiazolidinediones: an assessment from bench to bedside," Kidney International, vol. 70, no. 7, pp. 1223-1233, 2006.

[35] F. Zheng and Y. Guan, "Thiazolidinediones: a novel class of drugs for the prevention of diabetic nephropathy?" Kidney International, vol. 72, no. 11, pp. 1301-1303, 2007.

[36] T. Kanjanabuch, L.-J. Ma, J. Chen, et al., "PPAR- $\gamma$ agonist protects podocytes from injury," Kidney International, vol. 71, no. 12, pp. 1232-1239, 2007.

[37] R. Christensen, P. K. Kristensen, E. M. Bartels, H. Bliddal, and A. Astrup, "Efficacy and safety of the weight-loss drug rimonabant: a meta-analysis of randomised trials," The Lancet, vol. 370, no. 9600, pp. 1706-1713, 2007.

[38] R. M. Viner, Y. Hsia, T. Tomsic, and I. C. Wong, "Efficacy and safety of anti-obesity drugs in children and adolescents: systematic review and meta-analysis," Obesity Reviews. In press.

[39] L. L. Ioannides-Demos, J. Proietto, and J. J. McNeil, "Pharmacotherapy for obesity," Drugs, vol. 65, no. 10, pp. 1391-1418, 2005.

[40] M. Li and B. M. Y. Cheung, "Pharmacotherapy for obesity," British Journal of Clinical Pharmacology, vol. 68, no. 6, pp. 804810, 2009. 


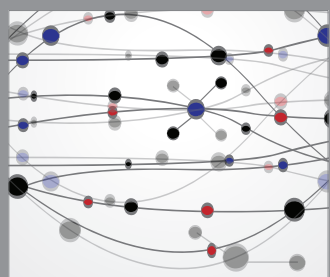

The Scientific World Journal
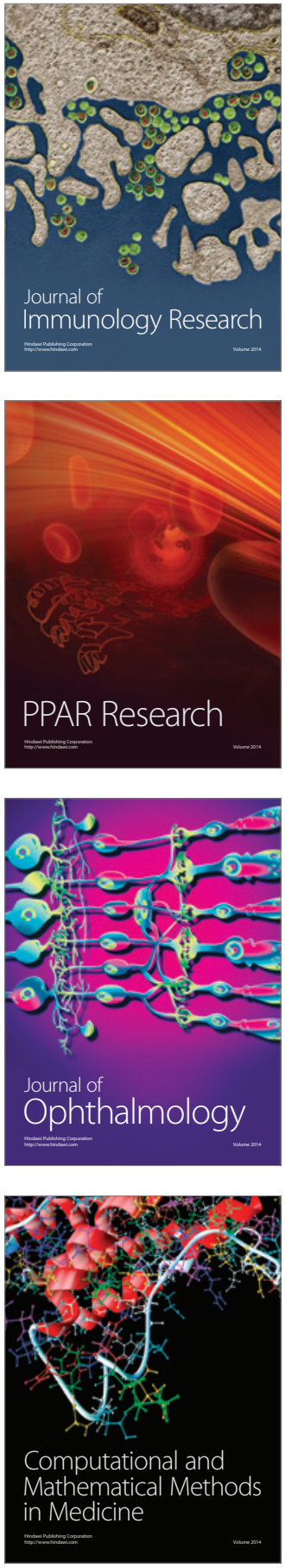

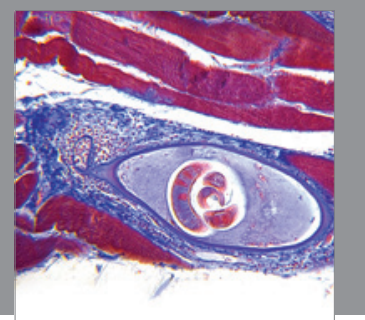

Gastroenterology

Research and Practice
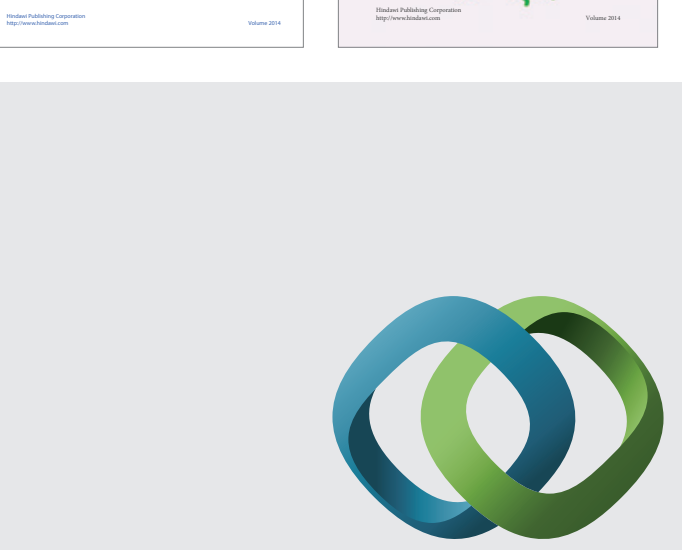

\section{Hindawi}

Submit your manuscripts at

http://www.hindawi.com
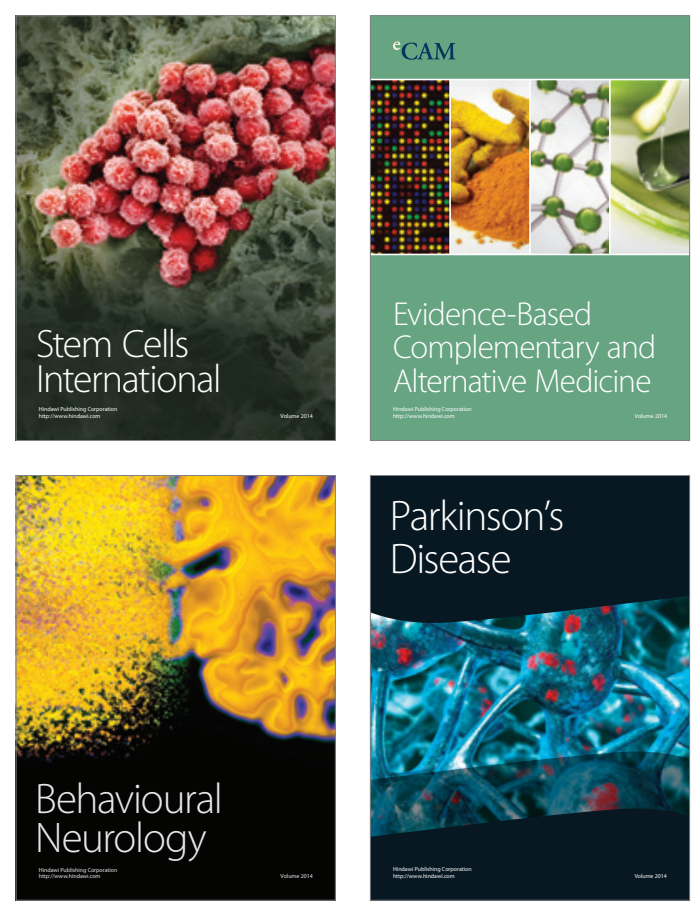

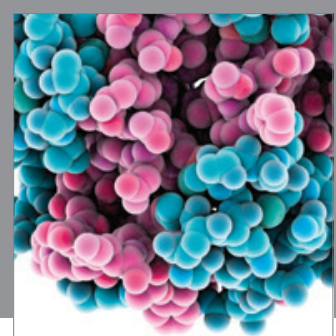

Journal of
Diabetes Research

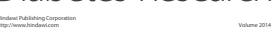

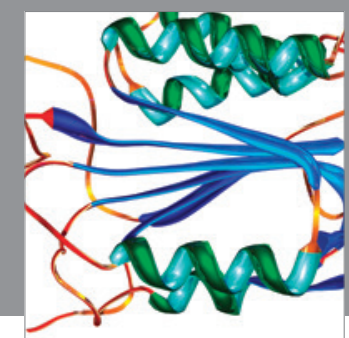

Disease Markers
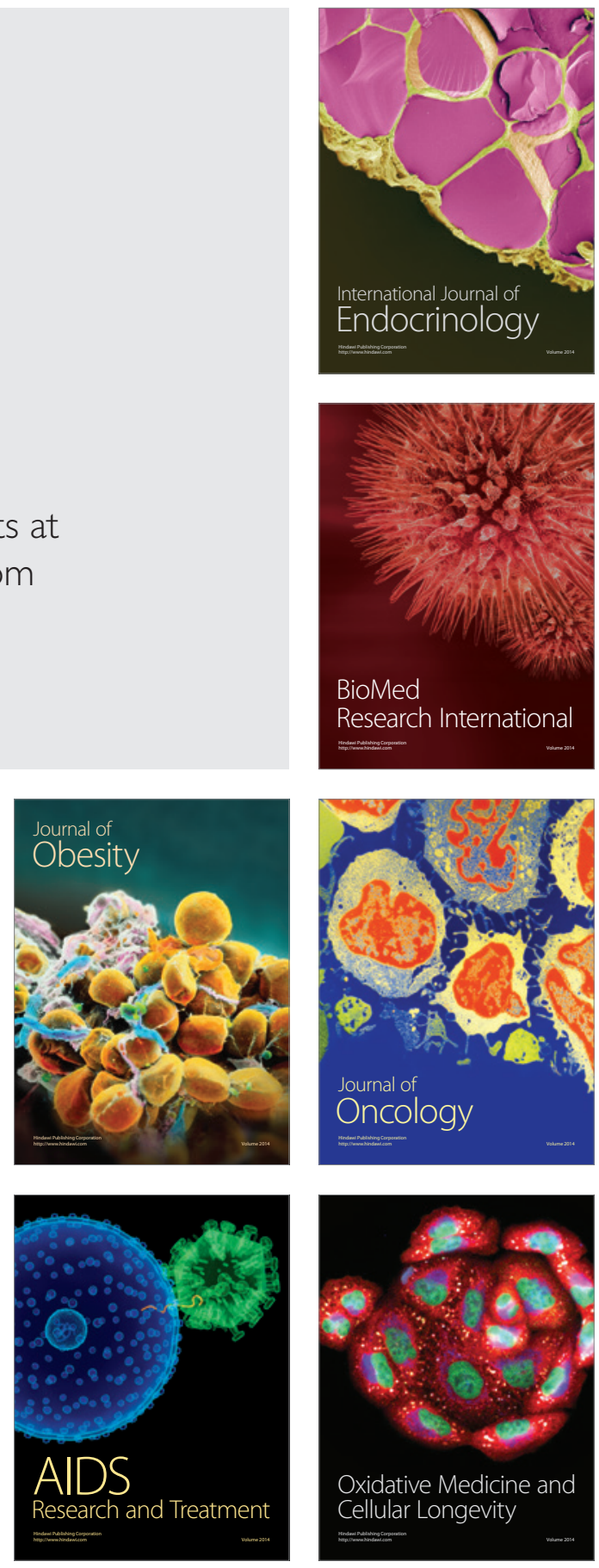